\title{
Evolution and organic geochemical significance of bicyclic sesquiterpanes in pyrolysis simulation experiments on immature organic-rich mudstone
}

\author{
Gang Yan ${ }^{1,2} \cdot$ Yao-Hui Xu ${ }^{1,2} \cdot$ Yan Liu ${ }^{3} \cdot$ Peng-Hai Tang ${ }^{1,2} \cdot$ Wei-Bin Liu ${ }^{4}$
}

Received: 22 February 2018 / Published online: 28 May 2019

(c) The Author(s) 2019

\begin{abstract}
Sesquiterpanes are ubiquitous components of crude oils and ancient sediments. Liquid saturated hydrocarbons from simulated pyrolysis experiments on immature organic-rich mudstone collected from the Lower Cretaceous Hesigewula Sag were analyzed by gas chromatography-mass spectrometry (GC-MS). $\mathrm{C}_{14}$ bicyclic sesquiterpanes, namely, $8 \beta(\mathrm{H})$-drimane, $8 \beta(\mathrm{H})$-homodrimane, and $8 \alpha(\mathrm{H})$-homodrimane were detected and identified on basis of their diagnostic fragment ions $(\mathrm{m} / \mathrm{z}$ $123,179,193$, and 207), and previously published mass spectra data, and these bicyclic sesquiterpanes presented relatively regular characteristics in their thermal evolution. The ratios $8 \beta(\mathrm{H})$-drimane $/ 8 \beta(\mathrm{H})$-homodrimane, $8 \beta(\mathrm{H})$-homodrimane $/ 8 \alpha(\mathrm{H})$ homodrimane, and $8 \beta(\mathrm{H})$-drimane $/ 8 \alpha(\mathrm{H})$-homodrimane all show a clear upward trend with increasing temperature below the temperature turning point. Thus, all these ratios can be used as evolution indexes of source rocks in the immature-lowmaturity stage. However, the last two ratios may be more suitable than the first ratio as valid parameters for measuring the extent of thermal evolution of organic matter in the immature-low-maturity stage because their change amplitude with increasing temperature is more obvious.
\end{abstract}

Keywords Immature-low-maturity stage $\cdot$ Simulated pyrolysis experiment $\cdot$ Bicyclic sesquiterpanes $\cdot$ Thermal evolution . Maturity indicators

\section{Introduction}

Bicyclic sesquiterpanes, a type of saturated hydrocarbon, are widely distributed in crude oil and sediments. The presence of bicyclic sesquiterpanes containing the drimane skeleton has been reported in many previous studies since Anders and Robinson (1971) first reported a series of bicyclic sesquiterpanes

Edited by Jie Hao

Yao-Hui Xu

yaohuixu@126.com

1 Key Laboratory of Exploration Technologies for Oil and Gas Resources (Yangtze University), Ministry of Education, Wuhan 430100, Hubei, China

2 College of Resources and Environment, Yangtze University, Wuhan 430100, Hubei, China

3 Institute of Mud Logging Technology and Engineering (Yangtze University), Jingzhou 434023, Hubei, China

4 Oil and Gas Survey, China Geological Survey, Beijing 100029, China in their study of the cycloalkane constituents of the Green River shale. They suggested that the bicyclic alkanes may have been derived from degradation of steroid or triterpenoid precursors. Philp et al. (1981) concluded that the distribution of $\mathrm{C}_{14}, \mathrm{C}_{15}$, and $\mathrm{C}_{16}$ bicyclanes was not dependent upon the degree of biodegradation of the oils. They also suggested that the tricyclic diterpenoid compounds might possibly be precursors of the bicyclanes or intermediates involved in their formation. Bendoraitis (1973) proposed that the high concentrations of bicyclic alkanes in crude oils from South Texas may result from the degradation of more complex precursors, in particular by the thermal degradation of higher plant triterpenes, whereas Alexander et al. (1984) proposed that bacteriohopanoids were extensively degraded in petroleum source rocks during diagenesis, resulting in functionalized bicyclic compounds of the drimane type. These compounds could then undergo rearrangement involving carbonium ion intermediates or be reduced directly to hydrocarbon. Noble et al. (1987) concluded that bicyclic alkanes were released from the insoluble organic matrix (kerogen) and that drimanes and 
homodrimanes occurred in sedimentary organic matter in both the free and the bound states.

The evaluation of thermal maturity of organic matter in the previous studies usually was carried out using vitrinite reflectance ( $\% R_{\mathrm{o}}$ ) (Zou et al. 2000; Wang et al. 2008; Hartkopf-Fröder et al. 2015; Fu et al. 2018), graptolite reflectance (Wang et al. 1993), pyrolysis $T_{\max }$ (Gao et al. 2018), production index (PI) values (Mashhadi et al. 2015), and some biomarkers parameters such as $T \mathrm{~s} /(T \mathrm{~s}+T \mathrm{~m})$ (Bao et al. 2018), moretane/hopane, oleanane/hopane, $\mathrm{C}_{29}$ 20S/(20S + 20R) (Fu et al. 2017). The bicyclic sesquiterpanes may also be very useful as direct maturity indicators during the immature-lowmaturity stage due to their relatively high sensitivity to subtle changes in organic matter. The aim of this study was to identify bicyclic sesquiterpanes and analyze their evolution and organic geochemical significance by conducting simulated pyrolysis experiments on an immature organic-rich Lower Cretaceous mudstone collected from the Hesigewula Sag, a relatively new exploration area.

\section{Samples and analytical methods}

\subsection{Sample}

The Hesigewula Sag is a Mesozoic sedimentary basin located in the northeastern Erlian Basin, China. The sag belongs to the Daxinganling stratigraphic subregion according to the formation. There are many strata in the periphery of this sag, including Jurassic, Cretaceous, and Upper Paleozoic. The sample for this experiment was collected from the Lower Cretaceous in Well HD2. This well is located at the Hesigewula Sag near the western edge of Daxinganling Prefecture. The source rock sample is brown gray mudstone, and the geochemical parameters of this sample are shown in Table 1.

\subsection{Simulated pyrolysis experiments}

In the experimental preparation phase, the source rock sample was crushed to $2 \mathrm{~mm}-4 \mathrm{~mm}$ and then pressed into a cylindrical shape with a pressure of $50 \mathrm{MPa}$ using a custom-made stamper. The weight, height, and diameter of the sample column were $145.22 \mathrm{~g}, 76.92 \mathrm{~mm}$, and $4.00 \mathrm{~cm}$, respectively.

The simulated pyrolysis experiment was carried out in an experimental system developed in-house, as shown in Fig. 1, and the experimental conditions are listed in Table 2. This simulation experiment mainly includes five steps:
(2) Put the sample column into the sealed pyrolysis vessel, evacuate the system using a vacuum pump, and then, fill the system with plenty of helium.

(3) Set the initial temperature and pressure of the experiment (Table 2), heat the reactor kettle with a thermowell, and keep the temperature and pressure unchanged for $24 \mathrm{~h}$.

(4) Let the experimental temperature drop rapidly to $150{ }^{\circ} \mathrm{C}$ and then collect the liquid and gaseous hydrocarbons.

(5) Set the next experimental temperature and pressure and repeat experimental steps 3 and 4 .

After flowing through a Geiser burette filled with silica gel and alumina (3:1), the liquid hydrocarbons and extractable organic matter (EOM) extracted from the original rock sample were separated into three gross compositions, saturated hydrocarbons, aromatic hydrocarbons, and nonhydrocarbons. Then, the saturated hydrocarbons were tested and analyzed with a gas chromatography-mass spectrometry (GC-MS).

\subsection{Analytical methods of GC-MS}

The GC-MS used was an Agilent-6890 N/5975 MSD. The column was an HP-5MS $(30 \mathrm{~m} \times 0.25 \mathrm{~mm} \times 0.25 \mu \mathrm{m})$, and the carrier gas used in this experiment was helium. The temperature of the injection port was set to $300{ }^{\circ} \mathrm{C}$. The pulse splitless injection technique was chosen as the injection mode, and the flow rate of the sample was kept unchanged at $1.0 \mathrm{ml} / \mathrm{min}$. The process of increasing temperature has two stages. Firstly, the temperature was kept at $50{ }^{\circ} \mathrm{C}$ for $1 \mathrm{~min}$ and then was increased to $100^{\circ} \mathrm{C}$ at a rate of $20^{\circ} \mathrm{C}$ per minute. Secondly, the temperature was increased to $315^{\circ} \mathrm{C}$ at a rate of $3{ }^{\circ} \mathrm{C}$ per minute and then remained unchanged for $16 \mathrm{~min}$. The mass spectrometer was an Agilent 5975 quadrupole mass spectrometer, and the temperature of the quadrupole rod was $150{ }^{\circ} \mathrm{C}$. The ion source of the mass spectrometer was an electron impact ionization source, with an energy of $70 \mathrm{eV}$ and a temperature of $230{ }^{\circ} \mathrm{C}$. The scanning methods were full scan (50 amu-550 amu) and selective ion scan.

(1) Clean the experimental system with dichloromethane.

Table 1 Geochemical parameters of the source rock sample

\begin{tabular}{llllllll}
\hline Depth, m & $R_{\mathrm{o}}, \%$ & TOC, $\%$ & $T_{\max },{ }^{\circ} \mathrm{C}$ & $\mathrm{S}_{1}+\mathrm{S}_{2}, \mathrm{mg} / \mathrm{g}$ & $\mathrm{HI}, \mathrm{mg} / \mathrm{g}$ & Kerogen type & Maceral compositions \\
\hline 108.60 & 0.47 & 6.00 & 430 & 17.29 & 284 & $\mathrm{II}_{1}$ & Exinite sapropelinite \\
\hline
\end{tabular}




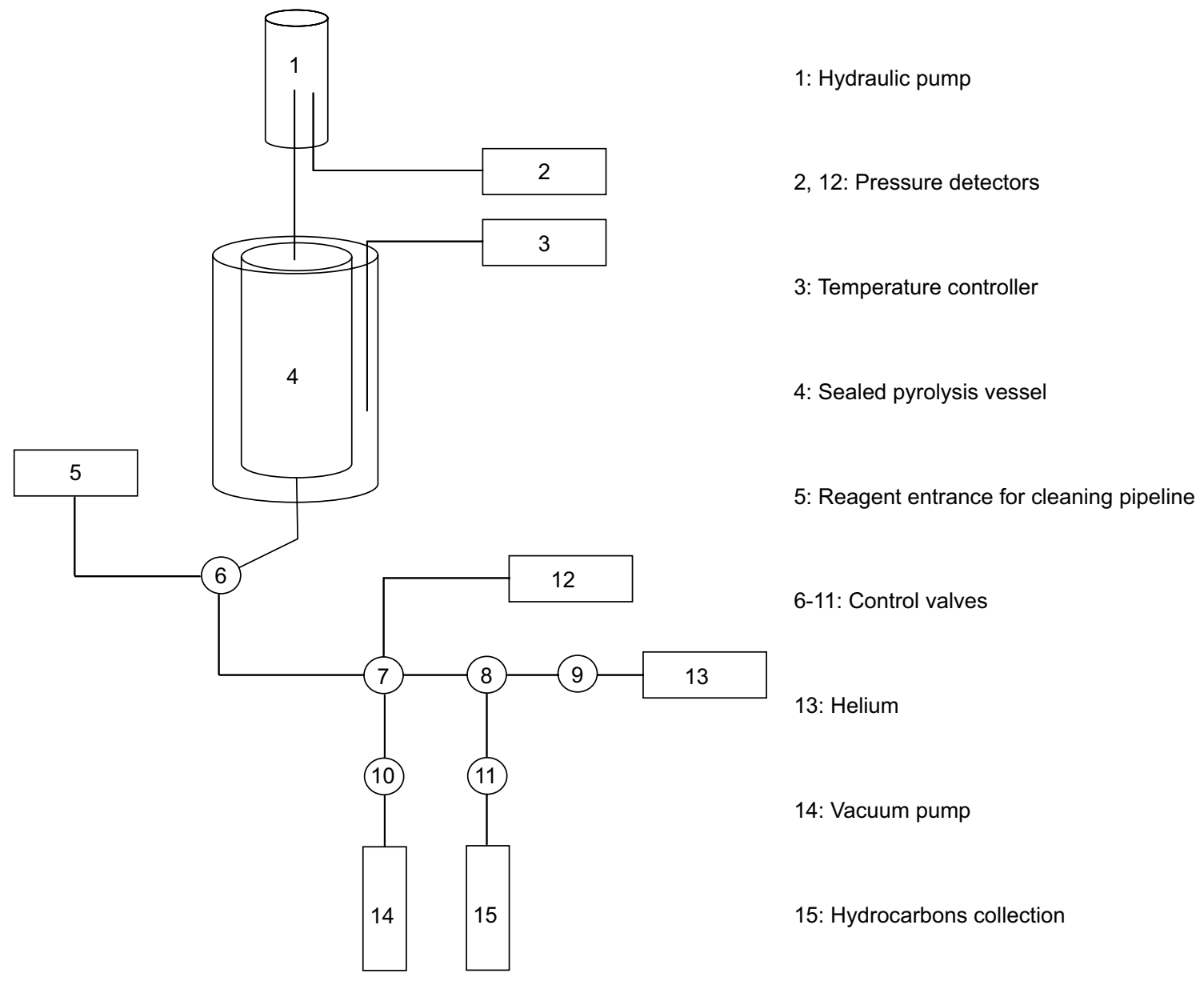

Fig. 1 System of simulated pyrolysis experiments

Table 2 Parameters of the simulated pyrolysis experiments

\begin{tabular}{lll}
\hline Temperature, ${ }^{\circ} \mathrm{C}$ & $\begin{array}{l}\text { Simulated stratum pressure, } \\
\text { MPa }\end{array}$ & $\begin{array}{l}\text { Fluid pres- } \\
\text { sure, MPa }\end{array}$ \\
\hline 280 & 51 & 6.55 \\
310 & 63 & 1.69 \\
340 & 78 & 1.42 \\
360 & 84 & 1.36 \\
380 & 93 & 1.42 \\
400 & 99 & 1.67 \\
435 & 108 & 2.04 \\
460 & 129 & 1.90 \\
485 & 144 & 1.88 \\
540 & 162 & 7.46 \\
\hline
\end{tabular}

\section{Results and discussion}

\subsection{Identification of the bicyclic sesquiterpanes}

Selected ion monitoring (SIM) of $\mathrm{m} / \mathrm{z} 123$ was used to determine whether any bicyclic sesquiterpanes were present in the saturated hydrocarbons separated from 10 products (Fig. 2). The sesquiterpanes ranging from $\mathrm{C}_{14}$ to $\mathrm{C}_{16}$ usually elute out between $n-\mathrm{C}_{13}$ and $n-\mathrm{C}_{16}$ in the total ion chromatograms (TIC)/SIM chromatogram (Figs. 2 and 3) (Philp et al. 1981; Stout et al. 2005; Wang et al. 2005a; Yang et al. 2009; Yessalina et al. 2006). Peaks A, B, C, and D were identified as $\mathrm{C}_{14}$ (peak A), $\mathrm{C}_{15}$ (peak B), and $\mathrm{C}_{16}$ (peaks $\mathrm{C}$ and $\mathrm{D}$ ) bicyclic sesquiterpanes (Fig. 3). Figure 3 shows that each of these products yields a notable $\mathrm{m} / \mathrm{z} 123$ fragment due to the formation of a $\mathrm{C}_{9} \mathrm{H}_{15}$ fragment ion (Fig. 4). The partial mass chromatograms of various confirmation fragment ions $(\mathrm{m} / \mathrm{z}, 179,193,207)$ for the different sesquiterpanes are also shown in Fig. 3, which aided in the confirmation of the identification of these compounds compared to previously published data (Alexander et al. 1983, 1984; Dimmler et al. 


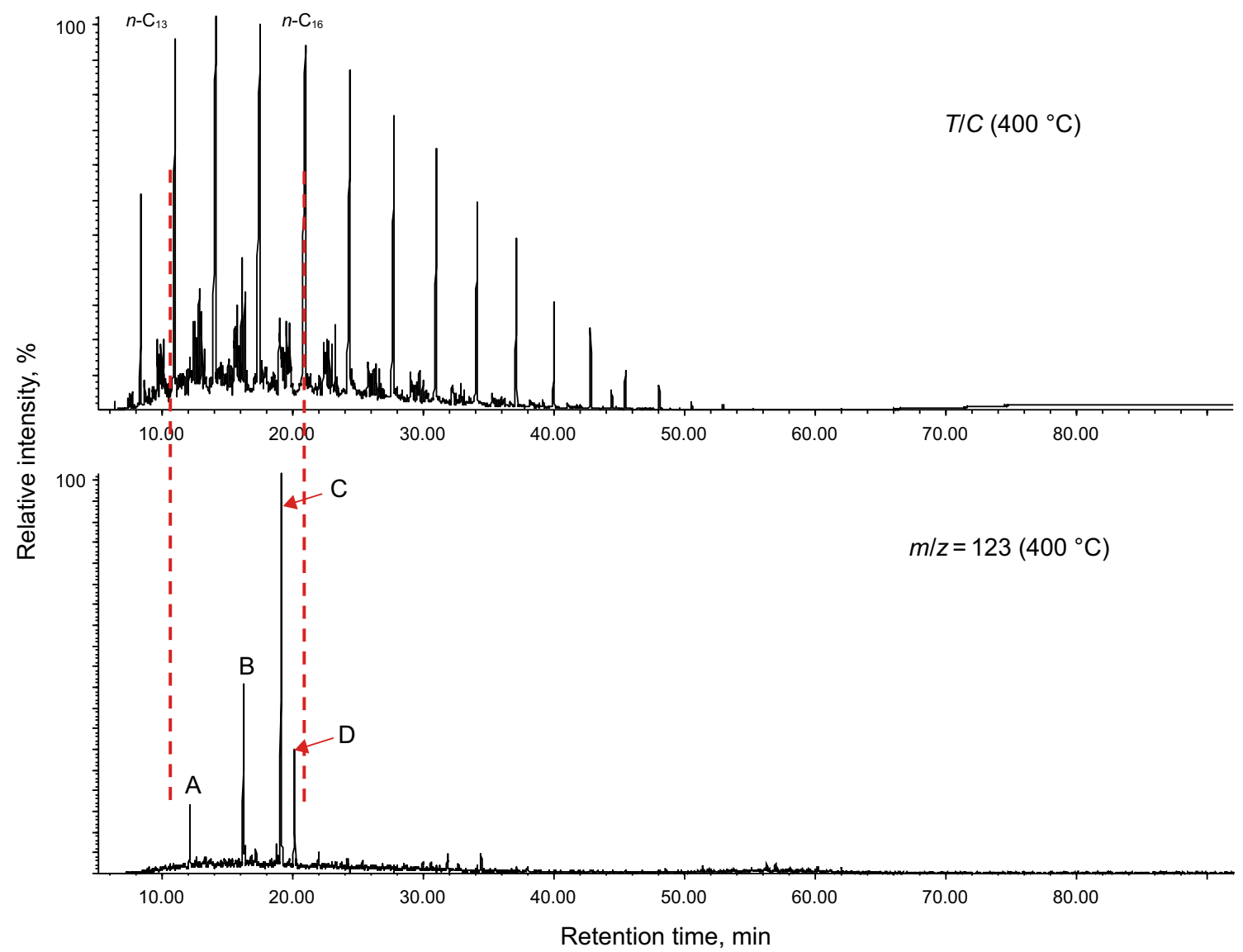

Fig. 2 Mass chromatogram of $m / z, 123$ and total ion chromatogram (TIC) of the saturated hydrocarbon of products $\left(400{ }^{\circ} \mathrm{C}\right)$. A C 14 bicyclic sesquiterpanes, B $8 \beta(\mathrm{H})$-drimane, C $8 \beta(\mathrm{H})$-homodrimane, D $8 \alpha(\mathrm{H})$-homodrimane

1984; Noble et al. 1987; Huang et al. 2004; Zhang et al. 2005; Wang et al. 2005b; Yang et al. 2009; Xu et al. 2010; Zhang and Zhang, 2012; Hou et al. 2013; Ji et al. 2016; Song et al. 2016; Cesar and Grice 2018), including mass spectral data, GC retention data, and the distribution pattern data of sesquiterpanes at $m / z 123$.

The mass spectra for the $\mathrm{C}_{14}, \mathrm{C}_{15}$, and $\mathrm{C}_{16}$ bicyclic sesquiterpanes usually show intense $\mathrm{M}^{+}-15$ fragment ions at $\mathrm{m} / \mathrm{z}$ 179, 193, and 207, respectively (Philp et al. 1981; Alexander et al. 1983,1984; Stout et al. 2005; Zhang et al. 2005).

In addition, a relatively intense ion at $m / z 123$ was present in the spectra. These ions were used in the present study as the initial basis for determining whether the $\mathrm{C}_{14}, \mathrm{C}_{15}$, and $\mathrm{C}_{16}$ bicyclic sesquiterpanes were detected. Moreover, the molecular ions of these compounds are also present in Fig. 5, i.e., $\mathrm{m} / \mathrm{z}$ 194,208 , and 222, corresponding to the molecular formulas of $\mathrm{C}_{14} \mathrm{H}_{26}, \mathrm{C}_{15} \mathrm{H}_{28}$, and $\mathrm{C}_{16} \mathrm{H}_{30}$, respectively. Peaks A, B, C, and $\mathrm{D}$ were identified as $\mathrm{C}_{14}$ bicyclic sesquiterpanes, $8 \beta(\mathrm{H})$ drimane, $8 \beta(\mathrm{H})$-homodrimane, and $8 \alpha(\mathrm{H})$-homodrimane, when a comparison was made between the present GC-MS data (Figs. 3 and 5) and the previously published literature data (Alexander et al. 1984; Dimmler et al. 1984; Noble 1986;
Noble et al. 1987; Jiang et al. 1988; Weston et al. 1989; Luo et al. 1990; Cheng et al. 1991; Wang 1993; Xia and Luo, 1994; Stout et al. 2005; Wang et al. 2005a; Zhang et al. 2005; Lu and Zhang 2008; Nytoft et al. 2009; Yang et al. 2012; Ji et al. 2015; Zhu et al. 2015).

Figure 6 shows the $\mathrm{m} / \mathrm{z} 123$ mass chromatograms of the extracts from the original source rock and 9 products at different experimental temperatures. Except for the extracts from the source rock, only a few species of bicyclic sesquiterpanes can be detected in other liquid hydrocarbons in the simulated pyrolysis experiment (Fig. 6). This study will investigate the evolution characteristics and geochemical significance of $8 \beta(\mathrm{H})$-drimane (peak B), $8 \beta(\mathrm{H})$-homodrimane (peak $\mathrm{C}$ ), and $8 \alpha(\mathrm{H})$-homodrimane (peak $\mathrm{D}$ ) considering their relatively high abundance and obvious change characteristics during thermal evolution.

\subsection{Evolution of bicyclic sesquiterpanes with increasing temperatures}

As shown in Fig. 6, there are many species of $\mathrm{C}_{14}, \mathrm{C}_{15}$, and $\mathrm{C}_{16}$ bicyclic sesquiterpanes present in the EOM extracted 


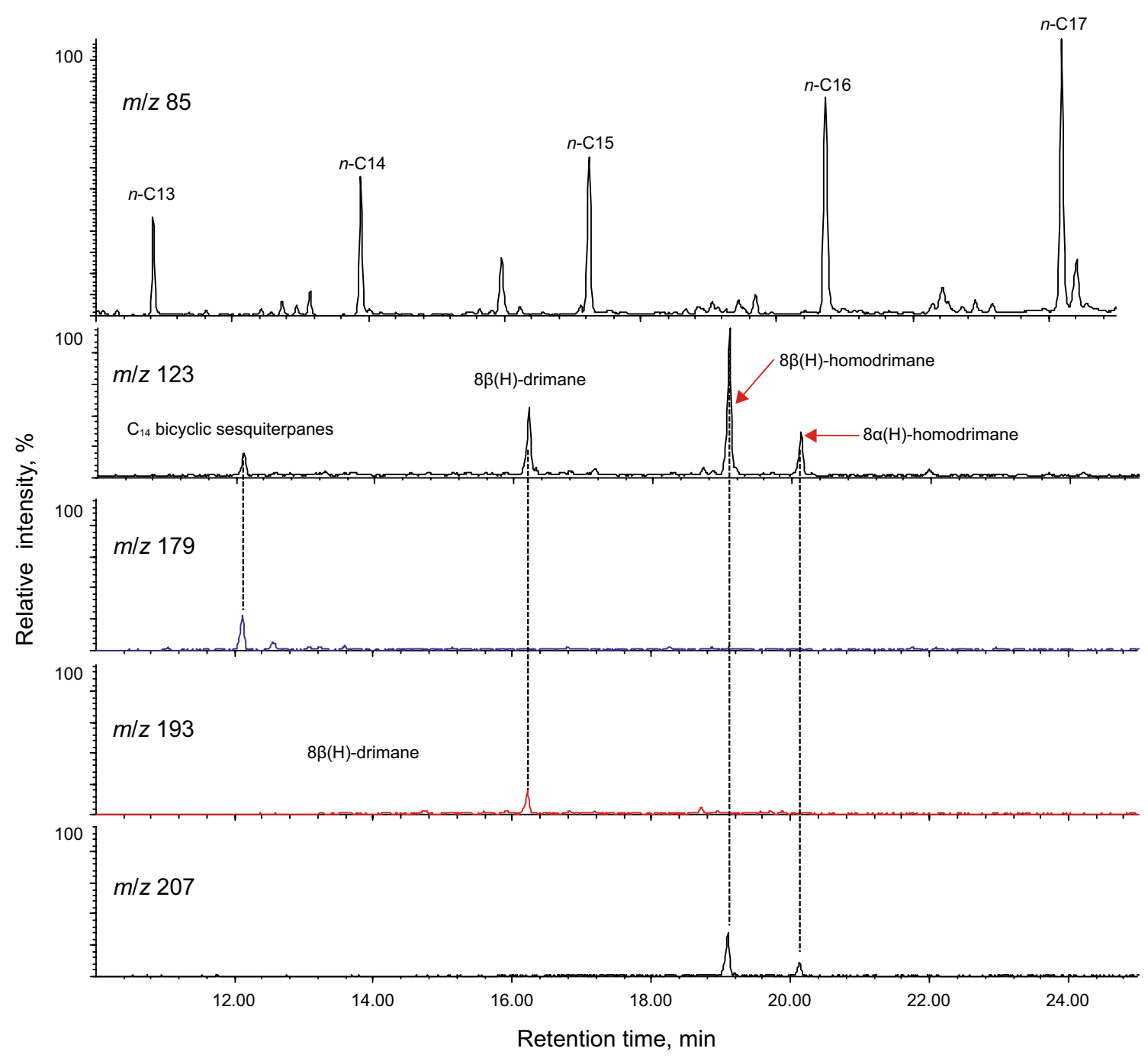

Fig. 3 GC-MS chromatograms of bicyclic sesquiterpanes $\left(\mathrm{m} / \mathrm{z}, 123,179,193\right.$, and 207) of saturated hydrocarbon (400 $\left.{ }^{\circ} \mathrm{C}\right)$ eluting in the $n$ - $\mathrm{C}_{13}$ and $n-\mathrm{C}_{16}$ range

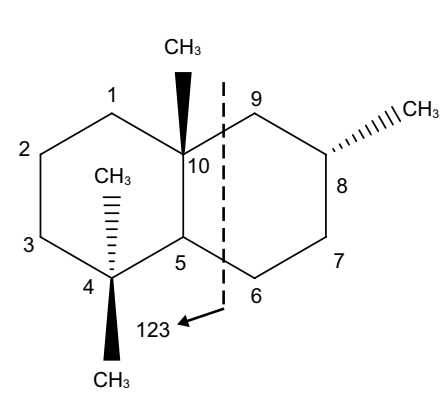

A

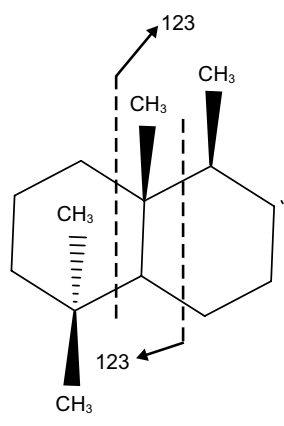

B

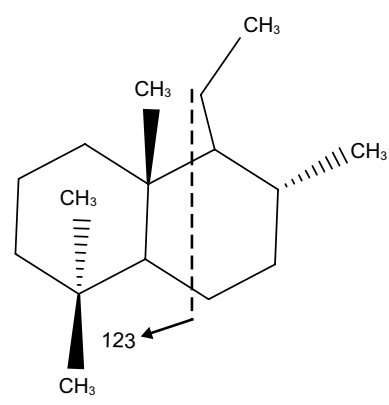

C

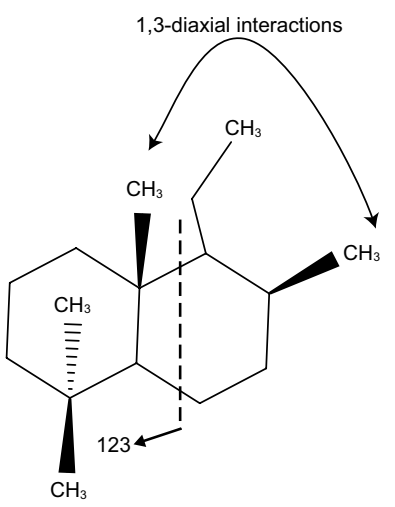

D

Fig. 4 Molecular structure of compounds A, B, C, and D. A C 14 bicyclic sesquiterpanes, B $8 \beta(\mathrm{H})$-drimane, C $8 \beta(\mathrm{H})$-homodrimane, D $8 \alpha(\mathrm{H})$ homodrimane 

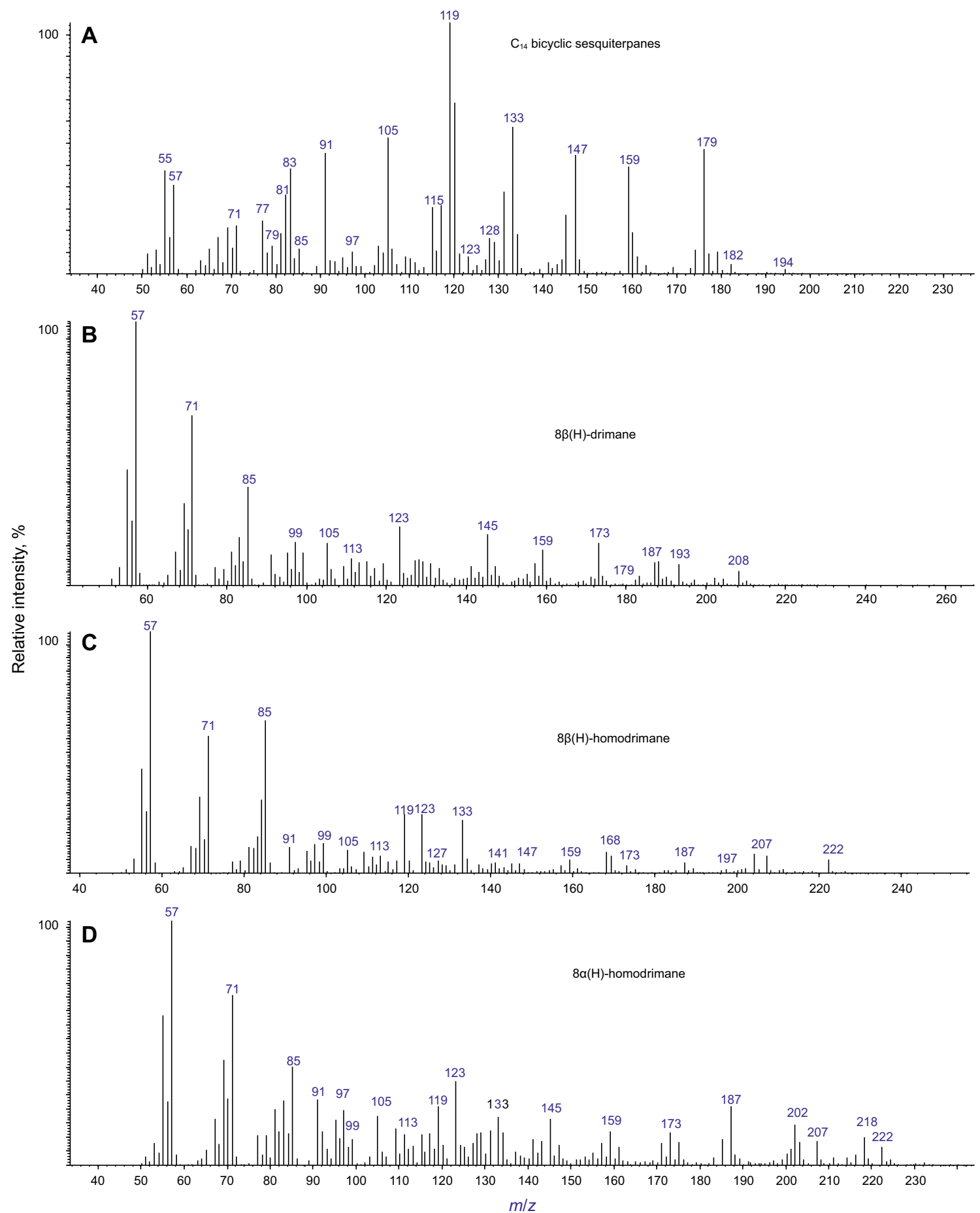

Fig. 5 Mass spectra of compounds corresponding to peaks A, B, C, and D. A $\mathrm{C}_{14}$ bicyclic sesquiterpanes, B $8 \beta(\mathrm{H})$-drimane, C $8 \beta(\mathrm{H})$ homodrimane, D $8 \alpha(\mathrm{H})$-homodrimane

from the source rock. However, only four types of predominant bicyclic sesquiterpanes (peaks A, B, C, and D) could be detected in the pyrolysis simulation products, and a small amount of $\mathrm{C}_{14}$ bicyclic sesquiterpanes could still be detected after $360^{\circ} \mathrm{C}$. Thus, the bicyclic sesquiterpanes may be derived from more complex drimane-related precursors by a rearrangement process involving carbonium ion intermediates during diagenesis and then turned into other hydrocarbons at lower experimental temperatures by thermal degradation because of their relatively poor thermal stability, except compounds A, B, C, and D. At the high experimental temperature $\left(\geq 360{ }^{\circ} \mathrm{C}\right)$ stage, 


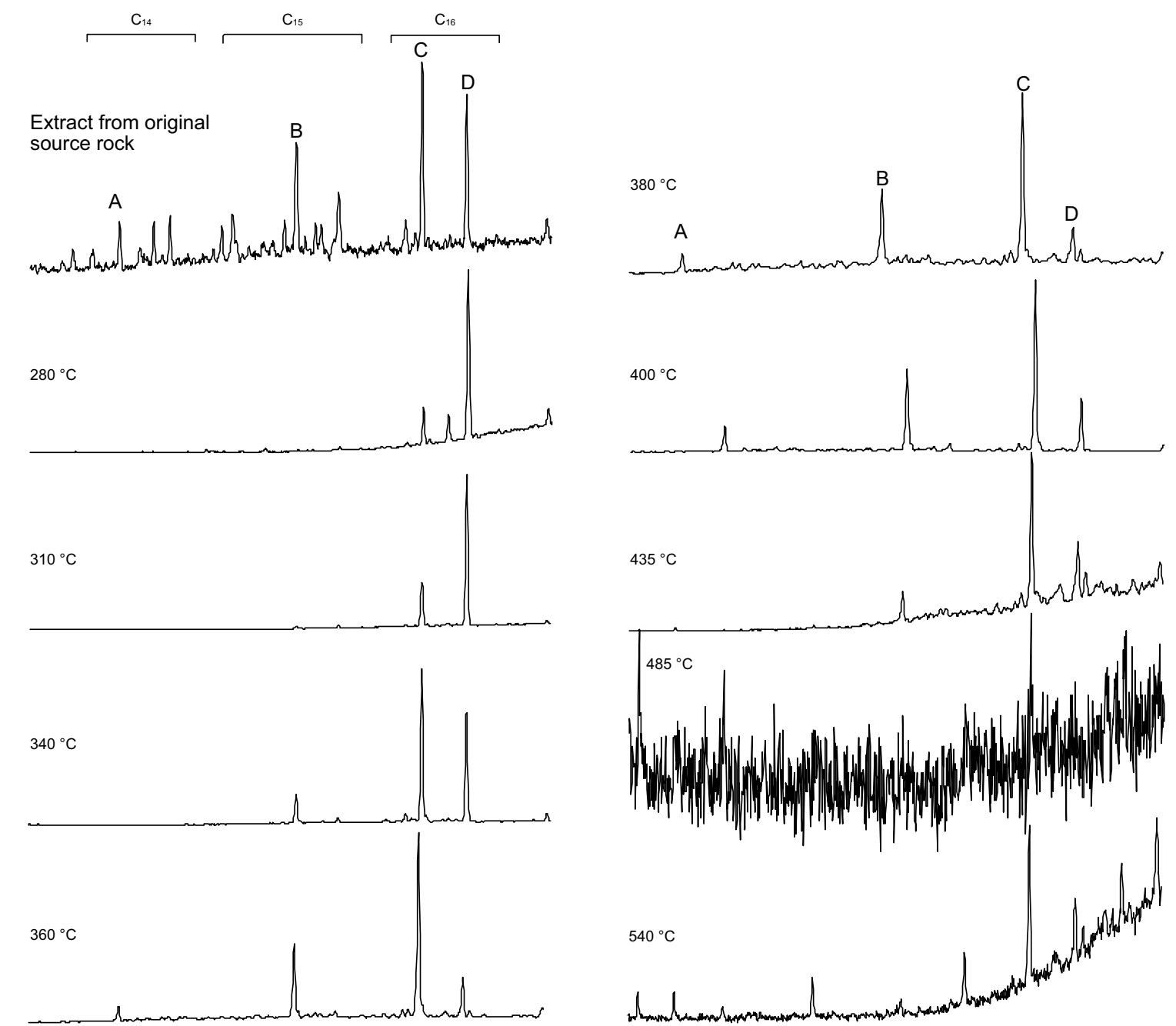

Fig. $6 \mathrm{~m} / z, 123$ mass chromatograms of the extracts from the original source rock and nine products. A $\mathrm{C}_{14}$ bicyclic sesquiterpanes, B $8 \beta(\mathrm{H})-$ drimane, C $8 \beta(\mathrm{H})$-homodrimane, D $8 \alpha(\mathrm{H})$-homodrimane

the low concentration of $\mathrm{C}_{14}$ bicyclic sesquiterpanes (peak A) shown in Fig. 6 may be derived from compounds B, C, and $\mathrm{D}$ by some secondary reactions, such as thermal degradation, methylation shift, and demethylation. In contrast, compounds B, C, and D have relatively good thermal stability, and their material sources are mainly derived from the pyrolysis products of kerogen, and only a small part of their material sources is derived from soluble organic matter (Xia and Luo 1994).

From Figs. 6 and 7, it is obvious that the relative abundance of bicyclic sesquiterpanes B, C, and D in liquid hydrocarbons in the experiment has a regular pattern of change. The relative abundance of $8 \beta(\mathrm{H})$-drimane shows an upward trend at first and then decreases with increasing experimental temperature, and the relative abundance of $8 \alpha(\mathrm{H})$ homodrimane presents a completely opposite trend. In addition, the relative abundance of $8 \beta(\mathrm{H})$-homodrimane first increases sharply and then remains unchanged after $360{ }^{\circ} \mathrm{C}$.

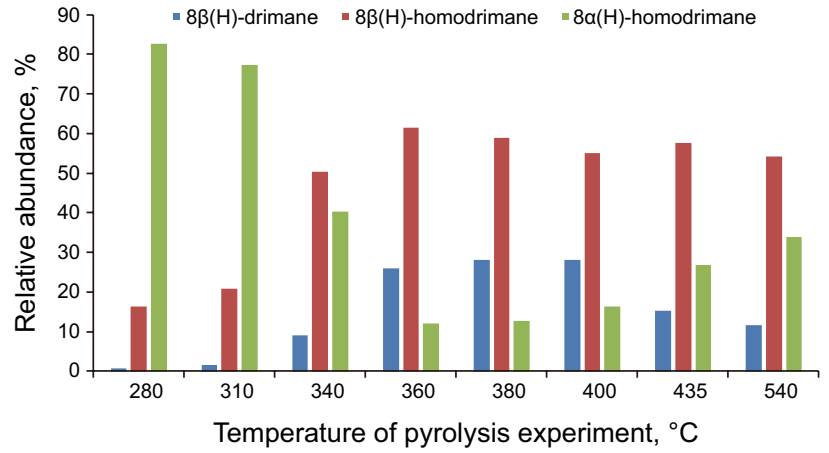

Fig. 7 Comparison of the relative abundance of the bicyclic sesquiterpanes at various temperatures 


\subsection{Discussion of maturity indicators for bicyclic sesquiterpanes}

To find suitable maturity indicators using compounds B, $\mathrm{C}$, and $\mathrm{D}$, ratios $8 \beta(\mathrm{H})$-drimane $/ 8 \beta(\mathrm{H})$-homodrimane, $8 \beta(\mathrm{H})$-homodrimane $/ 8 \alpha(\mathrm{H})$-homodrimane, and $8 \beta(\mathrm{H})$ drimane $/ 8 \alpha(\mathrm{H})$-homodrimane were calculated and discussed (Fig. 8).

Figure 8 clearly shows that all three selected indicators can reflect the evolution trend of organic matter, and all three parameters have the same change characteristics-a rapid increase at first and then a sharp decrease with increasing temperature. There is a conversion point between the two stages corresponding to a temperature of approximately $360{ }^{\circ} \mathrm{C}-380{ }^{\circ} \mathrm{C}$. Among the ratios, the tendency of the ratio $8 \beta(\mathrm{H})$-drimane $/ 8 \beta(\mathrm{H})$-homodrimane, which is widely used in geochemistry studies, is consistent with that in the study by Luo et al. (1990). Luo et al. (1990) found that the conversion point of the ratio $8 \beta(\mathrm{H})$-drimane $/ 8 \beta(\mathrm{H})$-homodrimane corresponds to $R_{\mathrm{o}}=1.25 \%$. Thus, it can be inferred that the $R_{\mathrm{o}}$ corresponding to the transformation point of the other two parameters is close to $1.25 \%$. In particular, the variation level of ratio $8 \beta(\mathrm{H})$-drimane $/ 8 \beta(\mathrm{H})$-homodrimane with increasing temperature is smaller than the other two indexes in this experiment, indicating that $8 \beta-(\mathrm{H})$-homodrimane $/ 8 \alpha(\mathrm{H})$ homodrimane and $8 \beta(\mathrm{H})$-drimane $/ 8 \alpha(\mathrm{H})$-homodrimane may be more suitable than the former ratio as a maturity parameter at the immature and low-maturity stages.

\subsection{Discussion of the possible formation mechanism of bicyclic sesquiterpanes}

The different thermal stabilities of these compounds lead to the abovementioned evolutionary characteristic (Figs. 7 and 8). The thermal stability of a compound depends on its molecular chemical structure. The molecular structures in Fig. 4 show that compounds $\mathrm{C}[8 \beta(\mathrm{H})$-homodrimane] and $\mathrm{D}[8 \alpha(\mathrm{H})$-homodrimane] have the same substituents and that the substitution positions of methyl and ethyl are exactly same. However, compound $\mathrm{D}[8 \alpha(\mathrm{H})$-homodrimane $]$ contains axial methyl groups at $\mathrm{C}-8$, which results in unfavorable 1,3-diaxial interactions with their respective $\mathrm{C}-10$ methyl groups (Fig. 4). In contrast, the C-8 methyl groups of the $8 \beta(\mathrm{H})$-epimers (compounds $\mathrm{C}$ ) are oriented in the lesscrowded equatorial positions, resulting in greater stability of the compounds $\mathrm{C}[8 \beta(\mathrm{H})$-homodrimane] (Wang et al. 2005a). Thus, compounds with the $8 \alpha(\mathrm{H})$ - configuration (compounds D) will be easily converted into stereoisomers with an $8 \beta(\mathrm{H})$ configuration (compounds $\mathrm{C}$ ) by isomerization reactions via an ionic mechanism owing to the greater stability of the latter (Noble et al. 1987). In addition, it is generally believed that compound $\mathrm{B}$ is formed by demethylation of compound

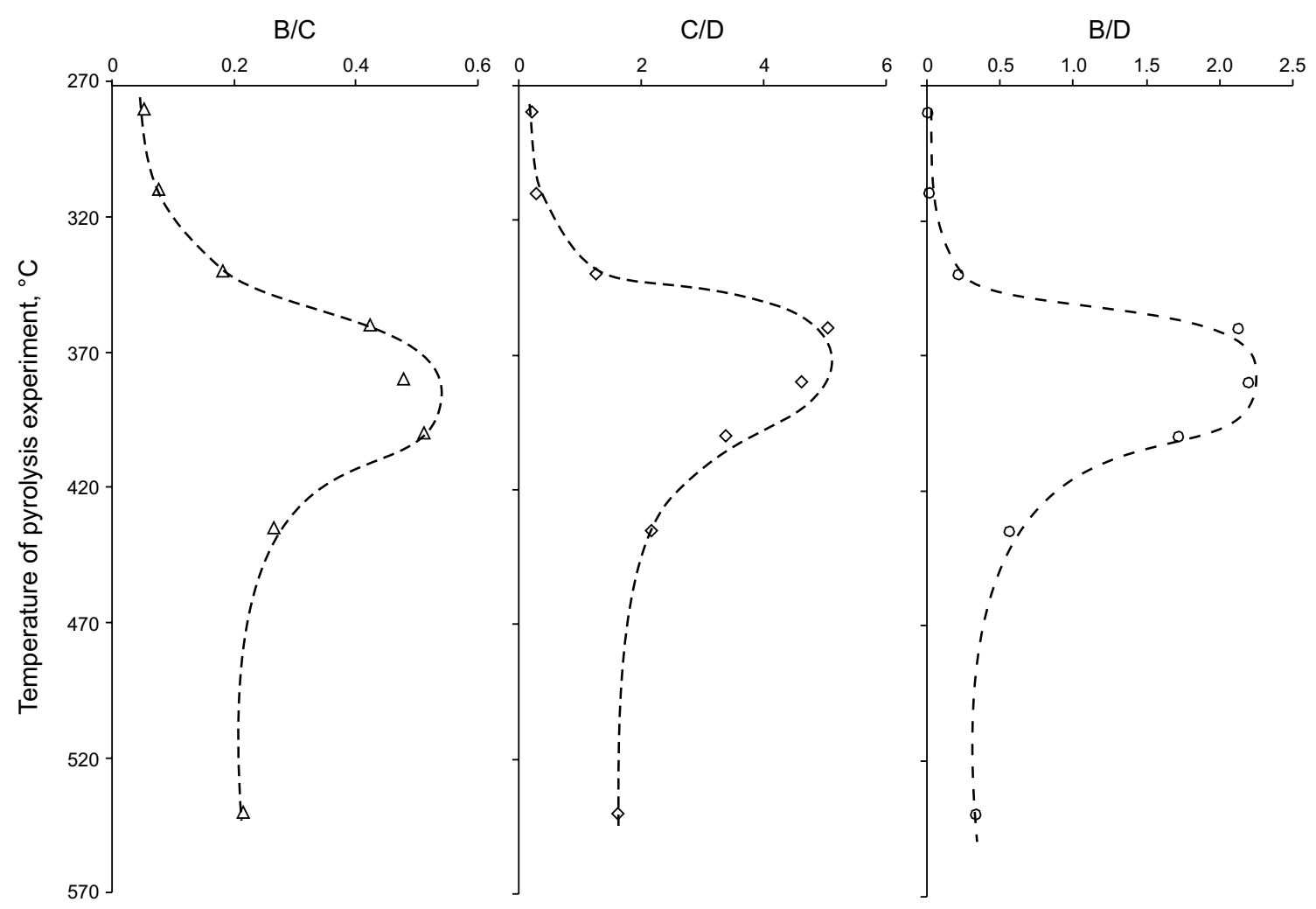

Fig. 8 Maturation index of bicyclic sesquiterpanes. B $8 \beta(\mathrm{H})$-drimane, C $8 \beta(\mathrm{H})$-homodrimane, D $8 \alpha(\mathrm{H})$-homodrimane 
C under thermodynamic activity (Xia and Luo, 1994), which can indicate that compound $\mathrm{B}$ is more thermostable than compound C. In summary, the thermal stability of these three compounds can be ranked as follows: $\mathrm{B}>\mathrm{C}>\mathrm{D}$, and this conclusion has been confirmed in the study by Xia and Luo, 1994. (Wang et al. 2005a). Therefore, during this experiment, with the increasing experimental temperature, a large amount of compound $\mathrm{D}$ converted to compound $\mathrm{C}$ by isomerization reactions and rearrangements at the beginning, and compound $\mathrm{C}$ simultaneously degraded into compound $\mathrm{B}$ by some secondary reactions, such as thermal degradation, methylation shift, and demethylation at the same time.

However, due to the low temperature (below $360^{\circ} \mathrm{C}$ ), the demethylation configuration conversion of compound $\mathrm{D}$ to compound $\mathrm{C}$ may be easier than the conversion of compound $\mathrm{C}$ to compound $\mathrm{B}$. Therefore, with the relative abundance of compound $\mathrm{D}$ decreasing sharply, the relative abundance of compound $\mathrm{C}$ increases significantly, and the relative abundance of compound B increases relatively gently (Fig. 6). The change in the relative abundance of all three compounds is not obvious from $360{ }^{\circ} \mathrm{C}$ to $400{ }^{\circ} \mathrm{C}$, which indicates that a large amount of hydrocarbon generation from kerogen makes a dynamic balance of this conversion process in this temperature range. At temperatures above $400{ }^{\circ} \mathrm{C}$, the relative abundance of compound $\mathrm{D}$ has an obvious upward trend. This phenomenon may be attributed to the release of these bicyclic alkanes from the insoluble organic matrix (kerogen) (Noble et al. 1987; Zhao et al. 2018) at this stage, and the rate of hydrocarbon expulsion is higher than the rate of conversion from compound $\mathrm{D}$ to compound $\mathrm{C}$. In addition, the relative abundance of compound $\mathrm{C}$ does not change significantly, indicating that the process of the formation of compounds $\mathrm{C}$ by isomerization reactions $(\mathrm{D} \rightarrow \mathrm{C})$ and the process of conversion $\mathrm{C} \rightarrow \mathrm{B}$ may reach a dynamic balance. However, the relative abundance of compound $\mathrm{B}$ shows a certain downward trend. There may be a massive conversion of compound B into low-carbon hydrocarbons in this temperature range, and this process likely led to a phenomenon in which a small number of species of $\mathrm{C}_{14}$ bicyclic sesquiterpanes can be detected at this stage.

\section{Conclusions}

The results of the simulated pyrolysis experiment show that the ratios $8 \beta(\mathrm{H})$-drimane $/ 8 \beta(\mathrm{H})$-homodrimane, $8 \beta(\mathrm{H})$-homodrimane $/ 8 \alpha(\mathrm{H})$-homodrimane, and $8 \beta(\mathrm{H})$ drimane $/ 8 \alpha(\mathrm{H})$-homodrimane show a regular upward trend at first and then decrease with increasing experimental temperature. This pattern is consistent with the thermostability of these three compounds, namely, $8 \beta(\mathrm{H})$-drimane $>8 \beta(\mathrm{H})$ homodrimane $>8 \alpha(\mathrm{H})$-homodrimane. At the first stage before the conversion point, a large amount of compound
D converted into compound $\mathrm{C}$, and compound $\mathrm{C}$ simultaneously demethylated to form compound B at the same time as the experimental temperature increased. Thus, the three selected parameters show the same upward trend. However, after the turning point, all three parameters show a downward trend, which may be due to the following two reasons; (1) In addition to the conversion of $\mathrm{D} \rightarrow \mathrm{C} \rightarrow \mathrm{B}$ during the high temperature phase, compound $\mathrm{B}$ will simultaneously convert to hydrocarbons of lower carbon numbers. (2) The hydrocarbons in the kerogen structure will be released in large quantities once this temperature is exceeded, leading to a substantial increase in the relative content of compound D.

The ratios $8 \beta(\mathrm{H})$-drimane $/ 8 \beta(\mathrm{H})$-homodrimane, $8 \beta(\mathrm{H})$-homodrimane $/ 8 \alpha(\mathrm{H})$-homodrimane, and $8 \beta(\mathrm{H})$ drimane $/ 8 \alpha(\mathrm{H})$-homodrimane all show a clear upward trend with increasing temperature before the temperature turning point. Therefore, all three parameters can be used as the maturity indicators of source rocks in the immature-lowmaturity stage. The last two ratios may be more suitable than the first ratio as valid parameters for measuring the extent of thermal evolution of organic matter in the immature-low-maturity stage because their amplitude of change with increasing temperature is more obvious.

Acknowledgements This work was supported by the National Natural Science Foundation of China (Grant Nos. 41672117 and 41503034), the Hubei Provincial Natural Science Foundation of China (Project No. 2017CFA027), the Open Subject of Shandong Provincial Key Laboratory of Depositional Mineralization \& Sedimentary Mineral (Baojun Liu Geoscience Science Foundation) (DMSM2017084), and the Open Subject of the State Key Laboratory of Petroleum Resources and Prospecting (PRP/open-1509). We thank Zhu CS for his suggestions and his help with the GC-MS experiments.

Open Access This article is distributed under the terms of the Creative Commons Attribution 4.0 International License (http://creativeco mmons.org/licenses/by/4.0/), which permits unrestricted use, distribution, and reproduction in any medium, provided you give appropriate credit to the original author(s) and the source, provide a link to the Creative Commons license, and indicate if changes were made.

\section{References}

Alexander R, Kagi R, Noble R. Identification of the bicyclic sesquiterpenes drimane and eudesmane in petroleum. J Chem Soc Chem Commun. 1983;5:226-8. https://doi.org/10.1039/c39830000226.

Alexander R, Kagi RI, Noble R, et al. Identification of some bicyclic alkanes in petroleum. Org Geochem. 1984;6:63-72. https://doi. org/10.1016/0146-6380(84)90027-5.

Anders DE, Robinson WE. Cycloalkane constituents of the bitumen from Green River Shale. Geochim Cosmochim Acta. 1971;35(7):661-78. https://doi.org/10.1016/0016-7037(71)90065 $-2$.

Bao JP, Zhu CS, Wang ZF. Typical end-member oil derived from Cambrian-Lower Ordovician source rocks in the Tarim Basin, 
NW China. Pet Explor Dev. 2018;45(6):1177-88. https://doi. org/10.1016/S1876-3804(18)30121-6.

Bendoraitis JG. Hydrocarbons of biogenic origin in petroleum-aromatic triterpenes and bicyclic sesquiterpenes. Adv Org Geochem. 1973;1974:209-24.

Cesar J, Grice K. Drimane-type compounds in source rocks and fluids from fluvial-deltaic depositional settings in the North-West Shelf of Australia. Org Geochem. 2018;116:103-12. https://doi. org/10.1016/j.orggeochem.2017.11.012.

Cheng KM, Jin WM, He ZH, et al. Application of sesquiterpanes to the study of oil-gas source-the gas-rock correlation in the Qiongdongnan Basin. J Southeast Asian Earth Sci. 1991;5(1-4):189-95. https://doi.org/10.1016/0743-9547(91)90025-s.

Dimmler A, Cyr TD, Strausz OP. Identification of bicyclic terpenoid hydrocarbons in the saturate fraction of Athabasca oil sand bitumen. Org Geochem. 1984;7(3-4):231-8. https://doi. org/10.1016/0146-6380(84)90119-0.

Fu JH, Deng XQ, Wang Q, et al. Densification and hydrocarbon accumulation of Triassic Yanchang Formation Chang 8 Member, Ordos Basin, NW China: evidence from geochemistry and fluid inclusions. Pet Explor Dev. 2017;44(1):48-57. https://doi. org/10.1016/S1876-3804(17)30007-1.

Fu ST, Fu JH, Yu J, et al. Petroleum geological features and exploration prospect of Linhe Depression in Hetao Basin, China. Pet Explor Dev. 2018;45(5):803-17. https://doi.org/10.1016/S1876 -3804(18)30084-3.

Gao G, Zhang WW, Ma GF, et al. Mineral composition and organic geochemistry of the Lower Cretaceous Xiagou Formation source rock from the Qingxi Sag, Jiuquan Basin, Northwest China. Pet Sci. 2018;15(1):51-67. https://doi.org/10.1007/s1218 2-017-0213-y.

Hartkopf-Fröder C, Königshof P, Littke R, et al. Optical thermal maturity parameters and organic geochemical alteration at low grade diagenesis to anchimetamorphism: a review. Int J Coal Geol. 2015;150:74-119. https://doi.org/10.1016/j.coal.2015.06.005.

Hou W, Yang BJ, Zheng L, et al. Change of bicyclic sesquiterpenes distribution in crude oils by simulated coastal oil spill biodegradation. Environ Chem. 2013;32(9):1639-45. https://doi. org/10.7524/j.issn.0254-6108.2013.09.006 (in Chinese).

Huang GH, Xiao ZY, Wang PR, et al. The occurrence and significance of terpenoids in Hade 4 oilfield and correlative areas, Tarim Basin. Nat Gas Geosci. 2004;15(2):128-32. https://doi.org/10.3969/j. issn.1672-1926.2004.02.006 (in Chinese).

Ji LM, Liang XF, He C, et al. Distribution of bicyclic alkanes of source rocks of Yanchang Formation in Xifeng area of Ordos basin and their biological sources. J Earth Sci Environ. 2015;37(1):7684. https://doi.org/10.3969/j.issn.1672-6561.2015.01.008 (in Chinese).

Ji L, He C, Zhang M, et al. Bicyclic alkanes in source rocks of the Triassic Yanchang Formation in the Ordos Basin and their inconsistency in oil-source correlation. Mar Pet Geol. 2016;72:359-73. https://doi.org/10.1016/j.marpetgeo.2016.02.021.

Jiang ZS, Philp RP, Lewis CA. Identification of novel bicyclic alkanes from steroid precursors in crude oils from Kelamayi oilfield of China. Geochim Cosmochim Acta. 1988;52(2):491-8. https://doi. org/10.1016/0016-7037(88)90104-4.

Lu SF, Zhang M. Geochemistry of oil and gas. Beijing: Petroleum Industry Press; 2008. p. 177-87 (in Chinese).

Luo BJ, Wang YX, Meng QX, et al. The geochemical significance of bicyclic sesquiterpanes in oil, coal and sediments. Sci China Ser B. 1990;4:419-30 (in Chinese).

Mashhadi ZS, Rabbani AR, Kamali MR, et al. Burial and thermal maturity modeling of the Middle Cretaceous-Early Miocene petroleum system, Iranian sector of the Persian Gulf. Pet Science. 2015;12(3):367-90. https://doi.org/10.1007/s12182-015-0040-y.
Noble RA. A geochemical study of bicyclic alkanes and diterpenoid hydrocarbons in crude oils, sediments and coals. Ph. D. Thesis, Department of Organic Chemistry, University of Western Australia. 1986.

Noble RA, Alexander R, Kagi RI. Configurational isomerization in sedimentary bicyclic alkanes. Org Geochem. 1987;11(3):151-6. https://doi.org/10.1016/0146-6380(87)90018-0.

Nytoft HP, Samuel OJ, Kildahl-Andersen G, et al. Novel $C_{15}$ sesquiterpanes in Niger delta oils; structural identification and potential application as new markers of angiosperm input in light oils. Org Geochem. 2009;40(5):595-603. https://doi.org/10.1016/j.orgge ochem.2009.02.003.

Philp RP, Gilbert TD, Friedrich J. Bicyclic sesquiterpenoids and diterpenoids in Australian crude oils. Geochim Cosmochim Acta. 1981;45(7):1173-80. https://doi.org/10.1016/00167037(81)90140-x.

Song X, Zhang B, Chen B, et al. Use of sesquiterpanes, steranes, and terpanes for forensic fingerprinting of chemically dispersed oil. Water Air Soil Pollut. 2016;227(8):281. https://doi.org/10.1007/ s11270-016-2981-1.

Stout SA, Uhler AD, McCarthy KJ. Middle distillate fuel fingerprinting using drimane-based bicyclic sesquiterpenes. Environ Forensics. 2005;6(3):241-51. https://doi.org/10.1080/15275920500194407.

Wang LQ, Bao JP, Ma DD, et al. Distributions and compositions of sesquiterpanoids and thermal maturation of organic matter in the lower mature source rocks. Geochimica. 2005a;34(2):173-9. https ://doi.org/10.3321/j.issn:0379-1726.2005.02.010 (in Chinese).

Wang PR. Biomarkers mass chromatography atlas. Beijing: Petroleum Industry Press; 1993. p. 11-8 (in Chinese).

Wang XF, Andreas H, Xiao JX, et al. Graptolite, chitinozoan and scolecodont reflectances and their use as indicators of thermal maturity. Acta Geol Sin Engl Ed. 1993;6(1):93-105. https://doi. org/10.1111/j.1755-6724.1993.mp6001006.x.

Wang YP, Zhao CY, Wang ZY, et al. Determining the main gasgeneration phase of marine organic matters in different occurrence states using the kinetic method. Acta Geol Sin Engl Ed. 2008;82(1):197-205. https://doi.org/10.1111/j.1755-6724.2008. tb00338.x.

Wang Z, Yang C, Fingas M, et al. Characterization, weathering, and application of sesquiterpanes to source identification of spilled lighter petroleum products. Environ Sci Technol. 2005b;39(22):8700-7. https://doi.org/10.1021/es051371o.

Weston RJ, Philp RP, Sheppard CM, et al. Sesquiterpanes, diterpanes and other higher terpanes in oils from the Taranaki basin of New Zealand. Org Geochem. 1989;14(4):405-21. https://doi. org/10.1016/0146-6380(89)90006-5.

Xia YQ, Luo BJ. The study on formation and evolution of bicyclic sesquiterpane by means of pyrolysis. Acta Sedimentol Sin. 1994;3:106-13 (in Chinese).

Xu Z, Zhang CM, Liu Q, et al. Distribution of bicyclic sesquiterpenes and its significance in Wen'an oilfield Jizhong depression. J Earth Sci Environ. 2010;32(4):368-71. https://doi.org/10.3969/j. issn.1672-6561.2010.04.007 (in Chinese).

Yang BJ, Zheng L, Zhang KY, et al. Oil fingerprint analysis of bicyclic sesquiterpanes by internal standard method and oil identification. J Instrum Anal. 2012;31(11):1421-5. https://doi.org/10.3969/j. issn.1004-4957.2012.11.014 (in Chinese).

Yang C, Wang ZD, Hollebone BP, et al. Characteristics of bicyclic sesquiterpanes in crude oils and petroleum products. J Chromatogr A. 2009;1216(20):4475-84. https://doi.org/10.1016/j.chrom a.2009.03.024.

Yessalina S, Suzuki N, Saito H. Geochemical characteristics of Tertiary Sagara oil from an active forearc basin, Shizuoka, Japan. Island Arc. 2006;15(3):292-303. https://doi.org/10.111 $1 /$ j.1440-1738.2006.00529.x. 
Zhang CM, Sun FJ, Lin Q, et al. Distribution of bicyclic sesquiterpanes in Q HD32-6 oilfield and its significance. China Offshore Oil Gas. 2005;17(4):228-30. https://doi.org/10.3969/j.issn.16731506.2005.04.003 (in Chinese).

Zhang WJ, Zhang M. Biomarker characteristics of saturated hydrocarbon in typical marine oils and typical coal-formed oils. J Oil Gas Technol. 2012;34(6):25-8. https://doi.org/10.3969/j.issn.10009752.2012.06.006 (in Chinese).

Zhao Y, Cai JG, Lei TZ, et al. A geochemical investigation of the free and carbonate-bound organic matter in the clay-sized fraction of argillaceous source rocks and its significance for biogenic interpretation. Pet Sci. 2018;15(4):681-94. https://doi. org/10.1007/s12182-018-0257-7.

Zhu YM, Xie JM, Sun LT, et al. Identification and geochemical significances of novel bicyclic and tetracyclic terpanes in crude oils from the Pearl River Mouth Basin. Geochimica. 2015;44(4):31322. https://doi.org/10.3969/j.issn.0379-1726.2015.04.001 (in Chinese).

Zou YR, Yang Q, Liu DM, et al. Maturity control on the patterns of hydrocarbon regeneration from coal. Acta Geol Sin Eng Ed. 2000;74(2):370-4. https://doi.org/10.1111/j.1755-6724.2000. tb00476.x. 